hardenability, and, therefore, its potential value in the reduction of the amount of other alloying elements required, is another problem to which attention has been given.

The Jominy test itself has received careful scrutiny, and a most valuable standard procedure for carrying out such investigations drawn up. It must be realized immediately that, in this test, hardness measurements alone are made, and other mechanical properties, therefore, are not taken into consideration. It is well known, however, that these properties, the notchedbar test for example, may vary to a very considerable extent, even with the same steel, and in a condition of identical hardness; the 'temper-brittleness' of some nickel-chrome steels affords an excellent example of this fact. It is clear, then, that while the intelligent use of the end-quench hardenability test may be of great value in providing a preliminary classification of different types of steel, it is equally important to realize that it does not obviate the necessity for other tests where ductility and toughness are of importance.

In view of the 400 pages of papers submitted, the Committee has done well to publish an agreed statement of the principal conclusions reached.

In connexion with the reproducibility of the curves obtained from the Jominy test, it is concluded that the end-quench test is capable of yielding satisfactorily reproducible results provided that the material under test is homogeneous, and that these results are not appreciably affected by small changes in the conditions under which the test is carried out. The end-quench curves determined on different samples of the same ingot, whether forged or rolled to approximately the diameter of the specimen, generally show only small differences. Further, the curves determined on samples from different ingots of the same cast of steel also in general show only minor variations. A marked variation of hardenability may, however, exist across the section even of a single bar, and in general, though not invariably, the hardenability at the centre is less than that at the surface. The hardenability of a steel may also be slightly affected by a variation of the microstructure before quenching. An examination of the hardenability of a hyper-eutectoid chromiummolybdenum steel, for example, suggests that the amount and distribution of the free carbide has a significant effect.

In connexion with the relationship of hardenability and chemical composition, the Committee reports that a wide variation in end-quench hardenability may exist between different casts of steel produced to the same specification, and that even when the variation of composition is taken into account, the hardenability cannot always be calculated satisfactorily from a knowledge of this and the grain size. Dealing with the prediction of the hardness of quenched, and quenched and tempered, bars from hardenability curves, it is concluded that the hardness curves of an oil-quenched bar across its diameter cannot be derived consistently and with adequate accuracy from a single end-quench curve, but that the hardness of a quenched and tempered bar may be predicted satisfactorily from a test specimen which has been end-quenched and afterwards tempered. The combination of mechanical "properties obtained from steel that has been quenched and then tempered in the range $500^{\circ}-650^{\circ} \mathrm{C}$. depends on the hardness developed by quenching; but there are as yet serious difficulties in interpreting end-quench curves in terms of the ability of steels to attain any required combination of mechanical properties. Further, the transformation-temperature ranges of steels during continuous cooling can be determined approximately from a series of interrupted endquench tests.

The Committee, at first under the chairmanship of the late Dr. T. Swindon, and later under that of Mr. D. A. Oliver, has done an admirable piece of work. Where all are so good, it is invidious to pick out any one contribution, but the writer may, perhaps, be allowed to mention his own special interest in $\mathrm{Mr}$. T. F. Russell's theoretical treatment of the Jominy test.

Throughout this work the fullest acknowledgment is made to the previous researches of Grossman, Jominy and their collaborators. Further, Crofts and Lamont of the Union Carbide \& Carbon Research Laboratories, Niagara Falls, have delayed publication of their other early and extensive researches for inclusion in this publication.

Some idea of the scope of the interest shown in recent years is provided by a bibliography of 255 papers, all published between 1938 and 1944 .

F. C. T.

\section{SOCIAL VALUE OF WAR-TIME MEDICAL RESEARCH}

GIR ALEXANDER BIGGAM has published a $\checkmark$ valuable paper on "War-time Advances in Medicine which might be translated into Civil Practice" (Edin. Med.J., 53, 413; Aug. 1946). In a world war, he says, some medical problems become so important that solutions of them must be found at all costs and, during the Second World War, the attacks upon these problems led to important advances in our knowledge, especially in the practice of preventive medicine.

One of the greatest enemies of the Allied Forces overseas was malaria. It could be argued, in fact, that malaria was our greatest enemy, and it is still the most formidable of the epidemic diseases which attack man. Sir Alexander states that it caused, in Burma at the beginning of the recent war there, nearly half the total sickness experienced. Intensive research on methods of control was therefore imperative, and an enormous amount of research was done. It was greatly helped by volunteers who included members of the Friends Ambulance Unit, students at the University of Oxford, where the Army Malaria Research Unit was situated, and soldiers serving at the Army Medical College. Much research was done elsewhere, and notes upon it have appeared from time to time in Nature. The advent of D.D.T., which kills the mosquitoes, and of dimethyl phthalate and other repellents, and of mepacrine, paludrine and the latest addition to our antimalarial drugs, $S N$ 13276, have enormously increased our control of malaria. Sir Alexander tells us how these weapons were used in the Far East. His account may be compared with the fascinating story of the eradication of Anopheles gambice from Brazil by a team working for the Brazilian Government and the Rockefeller Foundation (see Nature, 153, 765; 1944), a remarkable feat which has been repeated by the same workers in Egypt, where, in the Nile Valley in Upper Egypt in 1943 , some 130,000 people died of malaria transmitted by this species of mosquito (see Rockefeller Founda- 
tion Report, 1946). A valuable account of the principles and methods of malaria control has also been given by Dr. G. Macdonald, director of the Ross Institute, in his "Notes on Malaria and its Control for Planters and Miners" (April 1946), a pamphlet which discusses, in addition to the principles and methods of control, the malarial parasite itself, its main carriers in the British Empire, the types of land associated with malaria in Malaya and the factors which affect the incidence of malaria.

Another major menace of the Allied Forces in the East was bacillary dysentery. In the British Forces this was treated with sulphaguanidine, but the United States medical men preferred sulphadiazine, which was, they claimed, more effective. Sulphaguanidine, however, is less likely to affect the kidney, and British opinion, therefore, considered that it was preferable in tropical countries where much fluid is lost by sweating and where the sufferer is often dehydrated. Sir Alexander discusses the use of sulphaguanidine, and also the use of D.D.T. against the flies which spread the organisms which cause bacillary dysentery.

Serious also was amcbic dysentery, and much experience of its control and treatment was gained. Sir Alexander especially mentions the cases which resist treatment; and the view that they do so because secondary pyogenic organisms, which infect the intestinal walls already damaged by Entamoba histolytica, render these cases intractable. He quotes the work of W. H. Hargreaves (Lancet, ii, 68 ; 1942), which indicates that a preliminary treatment with penicillin and a sulphonamide drug would remove these secondary organisms, so that the attack upon $\boldsymbol{E}$.histolytica with specific drugs such as emetine bismuth iodide, chiniofon, etc., then produces good results. Sir Alexander outlines the treatment which should be given.

Epidemic typhus was not a serious risk in Burma. Mite-typhus (scrub-typhus) was one of the greatest problems encountered in that country. The control of this disease, which is caused by Rickettsia orientalis and is transmitted by the larvæ of the mite Trombidium akamushi and perhaps by other species of this genus (see Nature, 157, 236; 1946), was helped by attacks upon the mite with dimethyl phthalate. The remarkable story of the mass production of the vaccine against this disease has been told by Fulton, F., and Joyner, L. (Lancet, Dec. 8, 1945, p. 729, and Buckland, F. E., et al., ibid., Dec. 8, 1945, p. 734. See also the Lancet, Sept. 8, 1945, p. 308). So serious was the menace of the disease that the production of this vaccine was given the highest priority. Special laboratories were rapidly erected, cotton rats, in the lungs of which the Rickettsia develops abundantly, were flown from the United States by the R.A.F., and the devoted work of volunteers, who took very considerable risks of severe illness or death during their work (the accidental infection of four of these workers is described by Van den Ende, M., et al. (Lancet, July 6, 1946, p. 4)), produced enough of the vaccine to inoculate a considerable number of troops in Burma. The collapse of Japan and the withdrawal of Allied troops from the areas in which the disease was prevalent have made it unlikely that the results of this mass inoculation will now give useful information; but research on the vaccine has not ceased.

The rest of Sir Alexander's article is devoted to notes on typhoid fever, only a few outbreaks of which occurred, to warnings about the use of sul- phonamides in the tropics where excessive sweating increases the risk of damage by these drugs to the kidney, to penicillin and to laboratory methods of the diagnosis of smallpox and other diseases. There are interesting notes on the importance of preventing sea-sickness in troops about to cross rough seas. Research done by the Medical Research Council in co-operation with military medical men showed that the most useful remedy for it was $1 / 100$ grain of hyoscine given one hour before embarking and repeated every six hours. If the dose has to be continued over a long period, it must be reduced.

In his note on the work of psychiatrists, Sir Alexander says that the successful placing of men, selected by psychological tests, was one of the successes of the recent war. Important also were centres for physical development. A final note on administration points out that medical personnel in an Army Medical Service are under complete administrative control, so that a study of this Service and of the results obtained by it is especially interesting now that a State medical service is to be introduced in Great Britain.

G. LAPAGE

\section{THE IRISH PILCHARD FISHERY}

$T$ HE fishery for pilchards (Sardina pilchardus, Wal.) off the coasts of Cornwall has been famous for many centuries, and also the French, Spanish and Portuguese fisheries for sardines, which are the same species of fish. It is not generally known, however, that there has been also, at various periods, a flourishing Irish pilchard fishery. The appearance of a detailed historical account of the Irish pilchard fishery is therefore particularly welcome as being at once interesting and instructive*.

An Irish pilchard fishery existed so far back as 1591 and probably earlier; but its activities can be traced with some degree of accuracy only from about the year 1611. This is done comprehensively and in detail in the body of the paper, and is admirably summarized at the end.

The records show that the pilchard, when it frequents Irish waters, does so mainly along the coasts of Waterford, Cork and Kerry, although it is by no means confined to those counties. But the fishery has always exhibited extreme fluctuations, and, in recent times, the pilchard appears to have forsaken Irish waters almost entirely from 1904 until 1935. In the latter year shoals began to reappear, and in 1940 pilchards were plentiful once more off Ireland.

Unfortunately, there appears to be no demand in Ireland now for this fish, either fresh or preserved, and a vast potential source of food is not being exploited. But pilchards are occasionally caught when herring and mackerel are being fished, and even then they are usually thrown back into the sea. Nevertheless, the day yet may come when pilchards will command a ready market, even in Ireland, and this record of what the author calls "pilchard years" will then be invaluable. In the meantime, his paper is an outstanding contribution to our knowledge of this fishery over a very long period, and one hopes that its appearance will stimulate someone in a position to do so to prepare a similar historical account of the Cornish pilchard fishery.

G. A. Steven

* Proc. Roy. Irish Acad., 51, B, No. 5. Pp. 81-120. The Irish Pilchard Fishery. By Arthur E. J. Went. (Dublin: Hodges, Figgi and Co., Ltd.; London: Williams and Norgate, 1946.) 28. 6d. 